\title{
Inhibition of Transforming Growth Factor- $\beta$ Activation Diminishes Tumor Progression and Osteolytic Bone Disease in Mouse Models of Multiple Myeloma
}

\author{
Ailing Lu, ${ }^{*}$ Manuel A. Pallero, ${ }^{*}$ Weiqi Lei, ${ }^{*}$ Huixian Hong, ${ }^{*}$ Yang Yang, ${ }^{*}$ Mark J. Suto, ${ }^{\dagger}$ and Joanne E. Murphy-Ullrich*
}

From the Department of Pathology, ${ }^{*}$ University of Alabama at Birmingham, Birmingham; and Southern Research, ${ }^{\dagger}$ Birmingham, Alabama

Accepted for publication

November 12, 2015.

Address correspondence to Joanne E. Murphy-Ullrich, Ph.D., Professor of Pathology, University of Alabama at Birmingham, G001A Volker Hall, 1720 Second Ave. S., Birmingham, AL 35294-0019. E-mail: murphy@uab.edu.

\begin{abstract}
Transforming growth factor (TGF)- $\beta$ supports multiple myeloma progression and associated osteolytic bone disease. Conversion of latent TGF- $\beta$ to its biologically active form is a major regulatory node controlling its activity. Thrombospondin1 (TSP1) binds and activates TGF- $\beta$. TSP1 is increased in myeloma, and TSP1-TGF- $\beta$ activation inhibits osteoblast differentiation. We hypothesized that TSP1 regulates TGF- $\beta$ activity in myeloma and that antagonism of the TSP1-TGF- $\beta$ axis inhibits myeloma progression. Antagonists (LSKL peptide, SRI31277) derived from the LSKL sequence of latent TGF- $\beta$ that block TSP1TGF- $\beta$ activation were used to determine the role of the TSP1-TGF- $\beta$ pathway in mouse models of myeloma. TSP1 binds to human myeloma cells and activates TGF- $\beta$ produced by cultured human and mouse myeloma cell lines. Antagonists delivered via osmotic pump in an intratibial severe combined immunodeficiency CAG myeloma model or in a systemic severe combined immunodeficiency CAG-heparanase model of aggressive myeloma reduced TGF- $\beta$ signaling (phospho-Smad 2 ) in bone sections, tumor burden, mouse IL-6, and osteoclasts, increased osteoblast number, and inhibited bone destruction as measured by microcomputed tomography. SRI31277 reduced tumor burden in the immune competent 5TGM1 myeloma model. SRI31277 was as effective as dexamethasone or bortezomib, and SRI31277 combined with bortezomib showed greater tumor reduction than either agent alone. These studies validate TSP1-regulated TGF- $\beta$ activation as a therapeutic strategy for targeted inhibition of TGF- $\beta$ in myeloma. (Am J Pathol 2016, 186: 678-690; http://dx.doi.org/10.1016/j.ajpath.2015.11.003)
\end{abstract}

The bone marrow microenvironment is critical in the pathogenesis and progression of multiple myeloma (MM). Drugs that target this microenvironment have improved patient survival. ${ }^{1}$ Transforming growth factor (TGF)- $\beta$ is a multifunctional growth factor elaborated by myeloma cells, immune cells, bone, and bone marrow stromal cells. TGF- $\beta$ supports progression of myeloma through its role in stimulation of IL-6, Th17/T regulatory $\mathrm{T}$ cell development, angiogenesis, hematopoietic suppression, and its inhibition of terminal osteoblast differentiation and stimulation of osteoclast survival. $^{2-5}$ These actions contribute to the osteolytic bone disease and immune dysregulation that characterize myeloma progression and morbidity. In addition, TGF- $\beta$ inhibits dendritic cell maturation in myeloma. ${ }^{6}$ TGF- $\beta$ is expressed at high levels by both myeloma and bone marrow stromal cells; however, TGF- $\beta$ does not directly suppress or stimulate myeloma cell growth. ${ }^{3,7}$
Rather, TGF- $\beta$ impacts myeloma progression through its effects on the tumor microenvironment through exacerbation of lytic bone disease, impairment of normal immune responses, and stimulation of angiogenesis. ${ }^{4}$ TGF- $\beta$ is also

\footnotetext{
Supported by grants from the Alabama Drug Discovery Alliance, the University of Alabama at Birmingham (UAB) Comprehensive Cancer Center (P30CA013148), a grant from the American Society for Hematology Bridge grant program with supporting funds from the Department of $\mathrm{Pa}-$ thology, and NIH grants 1R01CA175012 (J.E.M.-U.) and R01CA151538 (Y.Y.). The authors also acknowledge the support of the UAB Comprehensive Cancer Center Small Animal Imaging Shared Facility (P30CA013148), the Small Animal Phenotyping Core for the $\mu \mathrm{CT}$ analyses (P30DK056336) and the UAB Bone Histomorphometry Core.

A guest editor acted as the editor-in-chief for this manuscript. No person at the University of Alabama at Birmingham was involved in the peer review process or final disposition of this article.

Disclosures: None declared.
} 
critical for hypoxia-induction of myeloma cancer stem cell-like side populations. ${ }^{8}$

TGF- $\beta$ stimulates early osteoblast proliferation while blocking late-stage osteoblast differentiation and mineralization to reduce bone formation. ${ }^{9}$ TGF- $\beta$ also increases bone lytic activity through stimulation of RANKL secretion and enhancement of osteoclast survival. ${ }^{10,11}$ Therefore, TGF- $\beta$ is a therapeutic target in metastatic bone disease associated with breast and prostate cancers. Similarly, TGF$\beta$ activity is associated with lytic bone disease in myeloma. ${ }^{5}$ Moreover, TGF- $\beta$ inhibition restores terminal osteoblast differentiation to suppress myeloma growth. ${ }^{2}$ Bone marrow fibroblasts derived from myeloma patients secrete elevated levels of TGF- $\beta .^{12}$ Elevated TGF- $\beta$ in myeloma also impairs hematopoiesis by hematopoietic progenitor cells and mesenchymal stromal cells. ${ }^{13}$

These data suggest that blockade of TGF- $\beta$ signaling can both directly reduce tumor burden and improve the tumor microenvironment to reduce myeloma progression and lytic bone disease. Blockade of TGF- $\beta$ has been shown to be of benefit in myeloma models in vitro and in vivo. ${ }^{2,3}$ Blocking TGF- $\beta$ activity in the tumor microenvironment enhances antitumor immunity in hematological malignancies. ${ }^{4,14}$ Despite the importance of TGF- $\beta$ in myeloma bone disease and immune dysregulation, no TGF- $\beta$ antagonists are being developed for the treatment of myeloma. Most TGF- $\beta$ antagonists broadly target the active ligand, receptors, or downstream kinases and do not distinguish between homeostatic and disease-induced TGF- $\beta$, raising the potential for adverse effects (such as inflammation or carcinogenesis). A major point of TGF- $\beta$ regulation occurs during conversion of the latent precursor to the biologically active molecule: binding of the N-terminal latency-associated peptide prevents TGF- $\beta$ binding to its receptors, and this interaction must be disrupted for TGF- $\beta$ signaling to occur. Latent TGF- $\beta$ can be converted to the active form through multiple and complex mechanisms, which include proteolysis, binding to integrins, mechanical forces, viral or oxidative modification of the latent complex, or by binding to the secreted and extracellular matrix protein thrombospondin1 (TSP1). ${ }^{15-18}$ The mechanism that regulates latent TGF- $\beta$ activation can vary with tissue, cell type, and disease milieu.

We have developed a unique approach to selectively inhibit disease-related TGF- $\beta$ through targeting only the TGF- $\beta$ that is activated through binding to TSP $1 .{ }^{17,18}$ TSP1 is a matricellular protein whose expression is highly controlled and which regulates multiple cell functions involved in tissue repair processes, including adhesion, migration, angiogenesis, nitric oxide signaling, and growth factor activity. ${ }^{18-21}$ TSP1 is increased in the MM microenvironment, and it is up-regulated by factors associated with myeloma progression (insulin-like growth factor-1, IL-6, TGF- $\beta)^{22,23}$ TSP1 is increased in the bone marrow plasma of myeloma patients and is expressed by several myeloma cell lines. ${ }^{23,24}$ Myeloma cells express multiple TSP1 receptors, including CD138, calreticulin, CD47, and integrins. ${ }^{24,25} \mathrm{~A}$ conserved sequence, LSKL, in the latencyassociated peptide region of TGF- $\beta$ is required for latency, and LSKL also is a binding site for TSP1: binding of TSP1 to latent TGF- $\beta$ disrupts latency. ${ }^{26,27}$ We have used the tetrapeptide, LSKL, as a competitive antagonist to specifically block TSP1 binding to the latency-associated peptide and thus inhibit activation of latent TGF- $\beta$ in numerous in vitro and in vivo models of disease. ${ }^{28-31}$ Because TSP1activated TGF- $\beta$ inhibits osteoblast differentiation, ${ }^{32,33}$ we hypothesized that TSP1 increases biologically active TGF- $\beta$ in the myeloma bone marrow microenvironment and that the LSKL peptide represents a selective therapeutic approach to target disease-induced TGF- $\beta$, which contributes to myeloma progression.

In this study, we provide evidence that TSP1 is a major regulator of latent TGF- $\beta$ activation in the myeloma bone marrow microenvironment. Furthermore, we show that antagonism of the TSP1-TGF- $\beta$ pathway by small molecule SRI31277, based on the LSKL peptide, significantly reduces myeloma tumor burden, IL-6 levels, and osteolytic bone disease in mouse myeloma models. SRI31277 also enhances the activity of bortezomib. These data identify TSP1 as a new therapeutic target for regulating TGF- $\beta$ activity in myeloma and potentially in other cancers with osteolytic bone disease.

\section{Materials and Methods}

\section{Cells}

Human CAG myeloma cells, ${ }^{34}$ heparanase expressing CAG cells (CAG-hpse), ${ }^{35}$ and mouse 5TGM1 cells ${ }^{36}$ stably expressing luciferase, and RPMI 8226 and U266 human myeloma cells (ATCC, Manassas, VA) were from frozen stocks in the laboratories of Drs. Yang Yang and Ralph Sanderson, University of Alabama at Birmingham (UAB). Cells were cultured in RPMI 1640 with $10 \%$ fetal bovine serum, $2 \mathrm{mmol} / \mathrm{L}$ L-glutamine, $1 \mathrm{U} / \mathrm{mL}$ penicillin, and $10 \mu \mathrm{g} / \mathrm{mL}$ streptomycin. Hygromycin $(500 \mu \mathrm{g} / \mathrm{mL})$ or G418 $(100 \mu \mathrm{g} / \mathrm{mL})$ were used for selection of luciferaseexpressing mouse and human cells, respectively. Antibiotic was omitted during experiments or before harvesting cells for animal studies. Cells used in animal studies were $\mathrm{CD}_{138^{+}}$. Cells were tested routinely for Mycoplasma.

\section{Antibodies and Other Reagents}

The following antibodies were purchased: rabbit antiosteocalcin (Abcam Inc., Cambridge, MA); rabbit monoclonal anti-phosphorylated (phospho)-Smad2 (Ser465/467 no. 3108S; Cell Signaling Technology, Danvers, MA); rabbit anti-phospho-Smad2 for immunohistochemstry (catalog no. AB3849; Millipore, Billerica, MA) and rabbit polyclonal 
anti-Smad2/3 (catalog no. 07-408; Millipore); rabbit polyclonal anti- $\beta$-tubulin (Santa Cruz Biotechnology Inc., Dallas, TX); mouse monoclonal anti-glyceraldehyde-3-phosphate dehydrogenase (Abcam Inc.); mouse anti-human CD138 (Cell Sciences, Canton, MA); rabbit anti- $\beta$-actin (NB10056874; Novus Biologicals, Littleton, $\mathrm{CO}$ ), secondary antibodies conjugated with horseradish peroxidase (Jackson ImmunoResearch Laboratories Inc., West Grove, PA); and biotinylated secondary antibodies (Vector Laboratories, Burlingame, CA). Mouse anti-human TSP1 (Mab133) was generated in our laboratory. ${ }^{37,38}$ Rabbit antibody that recognizes human and mouse TSP1 (N-terminus) (AP8522A) was purchased from Abgent (San Diego, CA). VetOne dexamethasone was purchased from MWI Veterinary Supply (Boise, ID) and bortezomib (PS-341) from Selleckchem (Houston, TX).

\section{Peptide Synthesis}

Peptides (N-LSKL-NH ${ }_{2}$ ) were synthesized by AnaSpec, Inc., (San Jose, CA) and were $>95 \%$ pure by mass spectrometry. Peptide SRI31277 was synthesized by Biomatik USA (Wilmington, DE) (Supplemental Figure S1A).

\section{ELISA Kits}

The following enzyme-linked immunosorbent assay (ELISA) kits were used according to the manufacturer's instructions: the Human Kappa ELISA Quantitation Kit and Mouse IgG2b ELISA Quantitation Kit (Bethyl Laboratories, Inc., Montgomery, TX), Quantikine Mouse IL-6 Immunoassay and Human TGF- $\beta 1$ Quantikine ELISA kit (R\&D Systems, Minneapolis, MN), and MouseTrap Assay SB-TR103 (Immunodiagnostic Systems Inc., Fountain Hills, AZ).

\section{TSP1 Purification}

TSP1 was purified from outdated de-identified, pooled human platelets purchased from the American Red Cross (St. Louis, $\mathrm{MO}$ ). The protocol for TSP1 purification was modified, in that the gel filtration step was performed in a column equilibrated

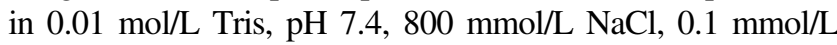
$\mathrm{CaCl}_{2}$. Pooled fractions were dialyzed against $0.01 \mathrm{~mol} / \mathrm{L}$ Tris, $\mathrm{pH} 7.4,0.15 \mathrm{~mol} / \mathrm{L} \mathrm{NaCl}$ (Tris-buffered saline), $0.01 \mathrm{mmol} / \mathrm{L}$ $\mathrm{CaCl}_{2}$. Residual TGF- $\beta$ activity in TSP1 fractions was analyzed by ELISA. Active TGF- $\beta$ in TSP1 preparations was $0.025 \mathrm{pmol} / \mathrm{L}$ per $\mu \mathrm{g}$ TSP1 (26 nmoles TSP1 trimer).

\section{Animals}

Male severe combined immunodeficiency (SCID) mice (8- to 10-week-old) were purchased from Harlan (C.B-17/lcrHsdPrkdc ${ }^{\mathrm{SCID}}$; Indianapolis, IN) or Charles River Labs (CB17/lcr-

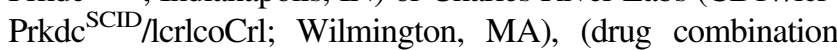
studies). C57BL/KaLwRij mice were obtained from Harlan (Horst, the Netherlands) and bred at UAB. All animal studies were conducted in Association for Assessment and Accreditation of Laboratory Animal Care-approved facilities under appropriate veterinary supervision and all protocols were approved by the UAB Institutional Animal Care and Use Committee.

\section{SCID Systemic Intravenous Model}

CAG-hpse myeloma cells stably expressing luciferase $\left(1.7 \times 10^{6}\right)$ were injected into the lateral tail vein. Animals are randomized to control and treatment groups based on serum human Ig kappa levels measured 10 to 12 days after tumor cell injection ( $n=10$ to 15 per group). Delivery of compounds via osmotic pump (eg, saline and peptides) or i.p. injection (dexamethasone $1 \mathrm{mg} / \mathrm{kg}$ once per week, bortezomib $1 \mathrm{mg} / \mathrm{kg}$ twice per week) was initiated 12 to 14 days after cell injection. Treatments were administered for 4 weeks with pump replacement with fresh drug at 2 weeks. Mice were euthanized approximately 4 weeks after initiation of treatment (6 weeks after tumor cell delivery) or at the first signs of distress. Tumor burden was assessed by monitoring human Ig kappa by ELISA and by whole body bioluminescence imaging at 2, 4, and 6 weeks after tumor cell delivery. Osteoclast activity was monitored after 4 weeks of treatment using an ELISA for mouse serum tartrate-resistant acid phosphatase-5b. Mouse serum IL- 6 was measured after 4 weeks of treatment by ELISA. Tibiae were analyzed for bone density by microcomputed tomography $(\mu \mathrm{CT})$ and femurs by counting tartrate resistant acid phosphatase (TRAP)-positive osteoclasts and osteocalcin-positive osteoblasts per millimeter of bone surface. Femur sections were evaluated for phospho-Smad2 by immunohistochemistry.

\section{SCID Intratibial Model}

Studies were performed as described for the systemic intravenous model except that the CAG human myeloma cells stably expressing luciferase $\left(5 \times 10^{5}\right.$ cells in $100 \mu \mathrm{L}$ saline $)$ were injected directly into the marrow cavity of the right tibia.

\section{TGM1 Model}

The 5TGM1 model is a syngenic model of murine myeloma. ${ }^{39}$ Luciferase expressing 5TGM1 cells $\left(1 \times 10^{6}\right.$ cells) were injected into the lateral tail veins of 10 -week-old male $\mathrm{C} 57 \mathrm{BL} / \mathrm{KaLwRij}$ mice. Mice were randomized to saline or SRI31277-treated groups based on serum Ig2b levels at 6 days $(n=10$ each). Treatment with saline or SRI31277 (30 mg/kg per day) via osmotic pump was initiated on day 9 and continued for 27 days with a change of peptide and osmotic pump after 14 days.

\section{Bioluminescence Imaging}

Luciferase-expressing tumor cells were detected by bioluminescence imaging. Bioluminescence was measured by 
using the IVIS Imaging System 100 (Xenogen, Cranbury, $\mathrm{NJ}$ ) at the UAB Small Animal Imaging Shared Facility. Images were taken 10 minutes after i.p. injection of luciferin (luciferase substrate), mice were under anesthesia during imaging via inhalation of $3 \%$ isoflurane, and five mice were imaged simultaneously. Living Image software version 4.3.1 (PerkinElmer Life Sciences; http://www.perkinelmer. com/resources/software-downloads.xhtml) was used to acquire and analyze images. For signal quantification, a region of interest was selected manually over the signal intensity. The area of the region of interest was kept constant.

\section{Immunohistochemistry and Analysis of 0steoclasts and Osteoblasts}

Femurs were fixed in cold $4 \%$ paraformaldehydephosphate-buffered saline at $4{ }^{\circ} \mathrm{C}$ and decalcified with $10 \%$ EDTA, pH 7, before paraffin embedding. Deparaffinized and rehydrated sections were treated with $10 \mathrm{mmol} / \mathrm{L}$ sodium citrate buffer $\mathrm{pH} 6.0$ in an $80^{\circ} \mathrm{C}$ water bath for 10 minutes for antigen retrieval and then endogenous peroxidase blocked with $1 \%$ hydrogen peroxide, followed by incubation with $2 \%$ normal horse serum (Sigma, St. Louis, MO) in phosphate-buffered saline to block nonspecific binding. Sections were incubated with primary antibodies (anti-phospho-smad2 or anti-osteocalcin) at $4{ }^{\circ} \mathrm{C}$ overnight. After washing, appropriate biotinylated secondary antibodies were applied for 1 hour, followed by horseradish peroxidase-conjugated streptavidin (ABC kit, Vector Laboratories) for 30 minutes at room temperature. Peroxidase was visualized by 3, 3'-diaminobenzidine hydrochloride (DAB Substrate Kit; Vector Laboratories, Burlingame, CA). Nonimmune rabbit serum was used as a negative control. Slides were evaluated in a blinded fashion (A.L.). Anti-phospho-Smad2 images were analyzed using Nuance image-analysis software version 2.8.0 (PerkinElmer Inc., Waltham, MA), at the UAB Pediatrics Neonatology Core. Osteoclasts were stained for TRAP using the University of Rochester Center for Musculoskeletal Research protocol (Rochester, NY).

Osteocalcin-positive osteoblasts and TRAP-positive cells on the surface of trabecular bone in a region of interest 250 microns from the endocortical edge and growth plate and extending $1 \mathrm{~mm}$ down the bone shaft were quantified using BIOQUANT Image Analysis software version 14.1.60 (BIOQUANT Image Analysis Corp., Nashville, TN) at the Histomorphometry and Molecular Analysis Core (UAB).

\section{$\mu \mathrm{CT}$ Analysis of Trabecular Bone}

Tibiae were fixed in $4 \%$ paraformaldehyde and kept in phosphate-buffered saline until scanning. Bones were scanned using microcomputed tomography (Scanco $\mu \mathrm{CT} 40$; Scanco Medical, Brüttisellen, Switzerland) at the UAB Small Animal Phenotyping Core.

\section{Western Blot Analysis}

Standard protocols were used, and specific conditions are described in the figure legends. Both attached and suspended cells were collected in $\times 2$ Laemmli buffer (catalog number 1610737; BioRad, Hercules, CA) with protease and phosphatase inhibitors. Immunoreactive bands were detected by enhanced chemiluminescence (PerkinElmer Life Sciences). Membranes were stripped with ReBlot Plus (Chemicon International, Temecula, CA) and reprobed with rabbit anti- $\beta$-tubulin, rabbit anti- $\beta$-actin, or mouse monoclonal anti-glyceraldehyde-3-phosphate dehydrogenase for loading controls. Densitometric analysis was performed using Kodak Molecular Imaging Software Standard edition software version 4.5 (Carestream Health Inc., Rochester, NY) or ImageJ software (NIH, Bethesda, MD; http://imagej.nih.gov/ij).

\section{In Vitro Studies with Bortezomib and Dexamethasone}

CAG-hpse cells were seeded at $2 \times 10^{5}$ CAG-cells in triplicate wells. Cells were pretreated with 50 or $100 \mathrm{nmol} / \mathrm{L}$ dexamethasone and 5,50 , or $100 \mathrm{nmol} / \mathrm{L}$ bortezomib for 1 hour, followed by incubation with $100 \mathrm{pmol} / \mathrm{L}$ TGF- $\beta$ or $20 \mu \mathrm{g} / \mathrm{mL}$ TSP1 in RPMI with $0.5 \%$ fetal bovine serum for 1 hour at $37^{\circ} \mathrm{C}$. Phospho-Smad2 in cell lysates was analyzed by Western blot analysis. For analysis of TSP1 (THBS1) mRNA, CAG-hpse cells cultured overnight in RPMI with $1 \%$ fetal bovine serum were treated with TGF- $\beta$, dexamethasone, or bortezomib for 6 hours. RNA was isolated with TRIzol reagent (15596-026, Life Technologies, Carlsbad, CA), reverse transcribed using PrimeScript RT Master Mix (RR036A, TakaraClontech, Mountain View, CA), and amplified with Premix Ex Taq (RR390L, Takara) using the following primers: THBS1 (Hs00962908_m1, Life Technologies) and Human GAPDH (4326317E, Life Technologies). Relative gene expression was calculated using the $2-\Delta \Delta \mathrm{Ct}$ method. Cells were treated as above for 12 hours in serum-free media and cell lysates analyzed for TSP1 for Western blot analysis.

\section{Statistics}

One-way analysis of variance was used for multiple comparisons and the unpaired Student's $t$-test was used for comparison of two samples. Analyses were performed using SigmaPlot software versions 4.0 and 13.0 (Systat Software, San Jose, CA) and GraphPad Prism software version 6.05 (GraphPad Software, Inc., La Jolla, CA) with $P<0.05$ considered significant. In drug combination studies, Dr. Sejong Bae (Comprehensive Cancer Center Statistical Core, UAB) provided assistance.

\section{Results}

TSP1 Activates MM Cell-Derived Latent TGF- $\beta$ in Vitro

The ability of TSP1 to activate latent TGF- $\beta$ expressed by myeloma cells was investigated in four different human 
myeloma cell lines and in one mouse myeloma line. The human cell lines express THBS1 message and TSP1 protein, albeit at low levels, whereas mouse thbs1 message was undetectable in the mouse 5TGM1 cells (data not shown). Addition of human TSP1 purified from platelets increased TGF- $\beta$ activity as measured by increased phospho-Smad 2 in the cell lysates of CAG human myeloma cells and in conditioned media from the more aggressive CAG-hpse myeloma cells (Figure 1, A and B). To confirm the role of TSP1 in regulating activation of myeloma-derived latent TGF- $\beta$, we used the LSKL peptide, which we had previously shown to block TSP1 binding to and activation of latent TGF- $\beta$ both in vitro and in vivo. ${ }^{26,31}$ In addition, we also tested a compound based on LSKL, SRI31277, which similarly blocks TSP1-TGF- $\beta$ activation in vitro in ELISAbased and cell-based assays (Supplemental Figure S1B) but that has improved pharmacokinetics with a $\mathrm{T}_{\max }$ of 0.5 hours and plasma half-life of 10.6 hours (data not shown). The TSP1 antagonist peptide, LSKL, but not a scrambled peptide (SLLK), reduced phospho-Smad2 in TSP1-treated MM cells (Figure 1A). Similarly, LSKL also blocked TSP1-TGF- $\beta$ activity in the conditioned media of CAG-hpse cells (Figure 1B). LSKL did not affect basal TGF- $\beta$ activity in untreated cells (data not shown). TSP1 also increased phospho-Smad 2 in RPMI 8226 cells, but not in U266 cells or mouse 5TGM1 myeloma cells: these cells also failed to respond to active TGF- $\beta$ stimulation (Figure $1 \mathrm{C}$ ). Interestingly, TSP1 increased active TGF- $\beta$ in the conditioned media of the TGF- $\beta$ nonresponsive U266 and 5TGM1 cells, and SRI31277 reduced active TGF- $\beta$ in all cell lines (Figure 1D). TSP1 increased absolute levels of active TGF- $\beta$ to a similar extent in all four cell lines (data not shown). These data

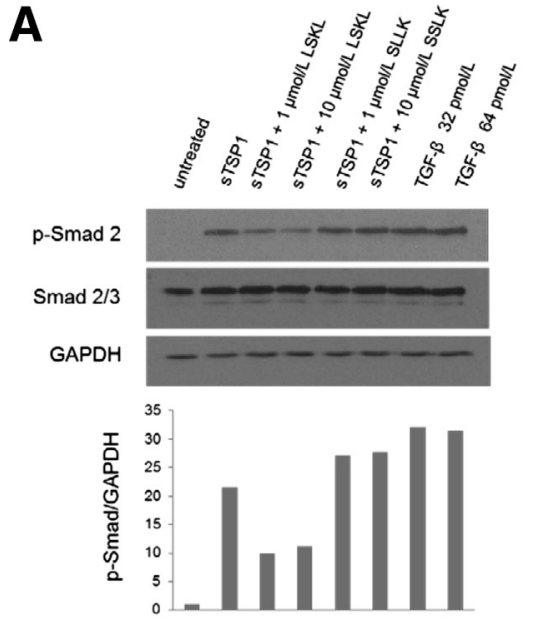

B
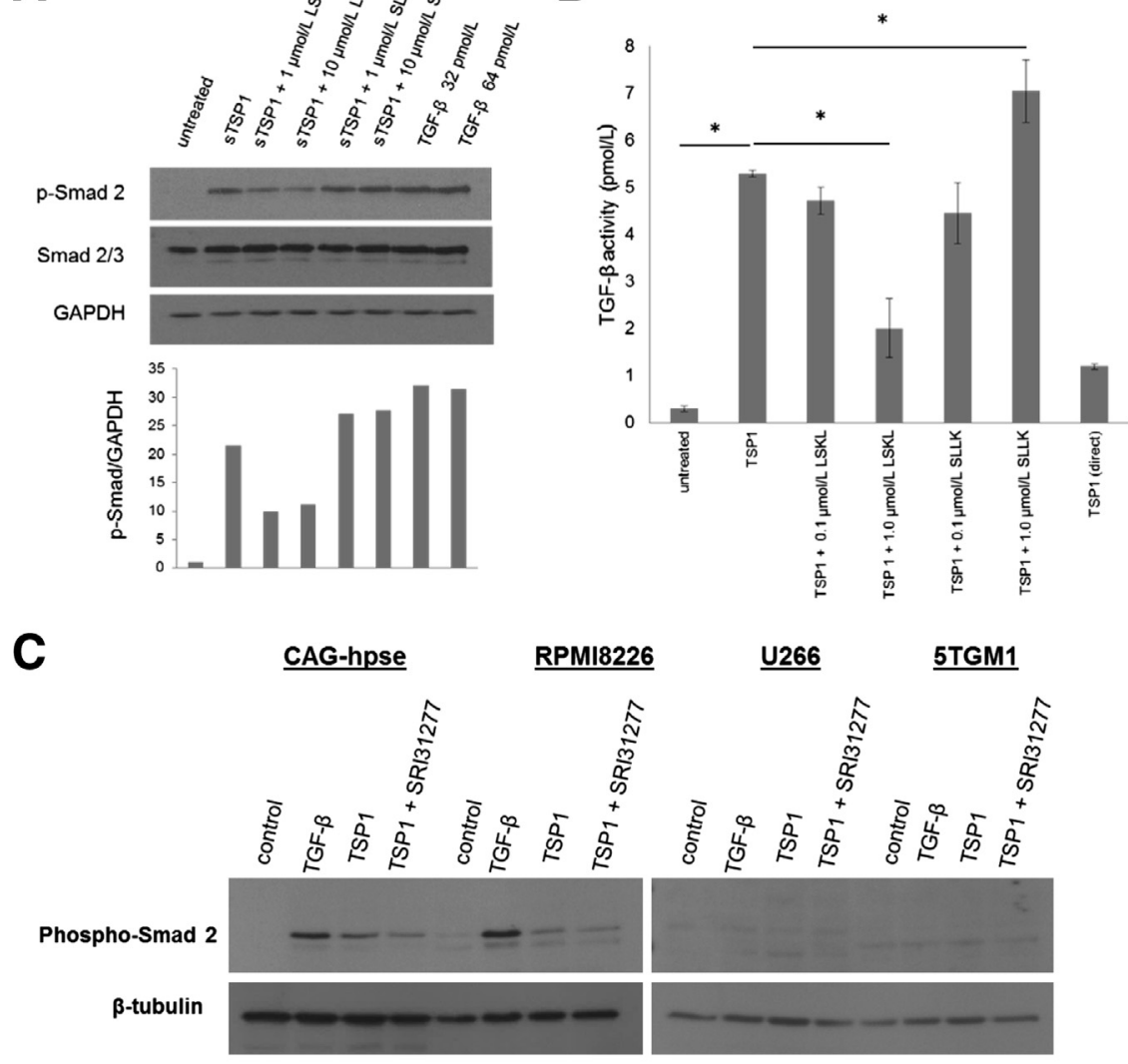

D

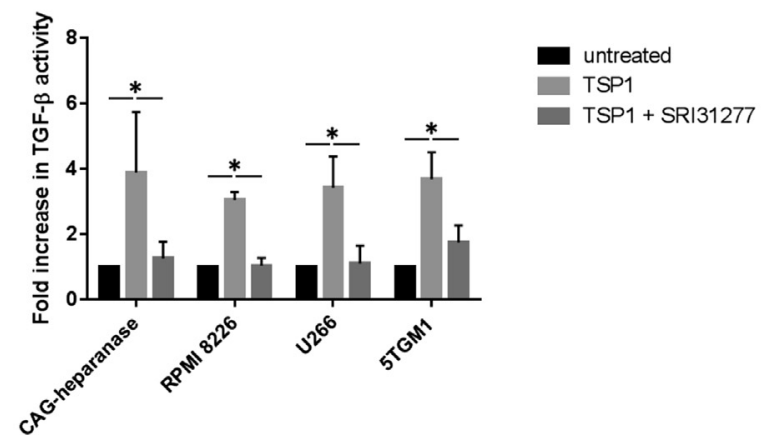

Figure 1 Thrombospondin1 (TSP1) binds and activates latent transforming growth factor (TGF) $\beta$ expressed by myeloma cells. A: CAG myeloma cells $\left(5 \times 10^{5}\right)$ were incubated with $10 \mu \mathrm{g} / \mathrm{mL}$ or 26 $\mathrm{nmol} / \mathrm{L}$ trimer TSP1 for 6 hours \pm LSKL or control peptide SLLK in RPMI with $2 \%$ fetal bovine serum (FBS). Cell lysates were immunoblotted for phospho-Smad2. Blots were stripped and reprobed for total Smad2/3 and glyceraldehyde-3-phosphate dehydrogenase (GAPDH). Results are normalized to GAPDH (untreated controls, 1). B: $5 \times 10^{5}$ heparanase expressing CAG (CAG-hpse) myeloma cells were treated with $20 \mu \mathrm{g} / \mathrm{mL}$ TSP1 \pm LSKL or 0.1 , $1.0 \mu \mathrm{mol} / \mathrm{L}$ SLLK in RPMI with $2 \%$ FBS for 4 hours. Conditioned media were assessed for TGF- $\beta$ activity using plasminogen activator inhibitor-1 promoter luciferase reporter assay. There is approximately $1.19 \mathrm{pmol} / \mathrm{L}$ TGF- $\beta$ in the added TSP1. Results are the means of triplicate determinations \pm SD. C: CAG-hpse, RPMI 8226, $\left(2 \times 10^{5}\right.$ cells) U266, and $\left(4 \times 10^{5}\right.$ cells) 5 TGM1 myeloma cell lines seeded in RPMI with $0.5 \%$ FBS were incubated with $20 \mu \mathrm{g} / \mathrm{mL}$ or $52 \mathrm{nmol} / \mathrm{L}$ trimer TSP1 or TSP1 with $0.5 \mu \mathrm{mol} / \mathrm{L}$ SRI31277 for 1 hour and cell lysates were probed for phospho-Smad2 by Western blot analysis. Membranes were reprobed with anti- $\beta$-tubulin to evaluate loading. D: Conditioned media also were assayed for active TGF- $\beta$ by enzyme-linked immunosorbent assay (results are the means $\pm \mathrm{SD}, n=$ 3 to 4 separate experiments). ${ }^{*} P<0.05$ by ANOVA with Holm-Sidak analyses (B) and by $t$-test with Holm-Sidak analyses (D). 
suggest that TSP1 can regulate activation of the latent TGF- $\beta$ secreted by MM cells, even in myeloma cells unresponsive to TGF- $\beta$.

\section{Effects of TSP1 and TSP1-Dependent TGF- $\beta$ Activation on MM Cell Proliferation}

TGF- $\beta$ did not alter proliferation of CAG-hpse myeloma cells as compared with growth in $1 \%$ fetal bovine serum (Supplemental Figure S2). TSP1 had a modest inhibitory effect on cell growth, but this was not reversed by a tripeptide version of LSKL (SRI31277) (Supplemental Figure S2). SRI31277 alone did not affect cell growth. These data show that TGF- $\beta$ and TSP1-dependent TGF- $\beta$ activation do not directly promote myeloma cell growth and suggest that the primary impact of TGF- $\beta$ in supporting myeloma progression is through its effects on the tumor microenvironment.

\section{Blocking TSP1-TGF- $\beta$ Activation Reduces Tumor Burden and Osteolytic Bone Disease in Vivo}

TGF- $\beta$ and TSP1-TGF- $\beta$ activation do not directly stimulate growth of human myeloma CAG-hpse cells in cell proliferation assays, suggesting the primary impact of TGF- $\beta$ in supporting myeloma progression is through its effects on the tumor microenvironment (Supplemental Figure S2). To test the role of
TSP1-TGF- $\beta$ activation on myeloma progression in the bone microenvironment, we used three different mouse models. In the SCID-tibia model, human CAG myeloma cells were injected directly into the marrow space of the right tibia. After 2 weeks, saline or LSKL peptide (30 mg/kg per day) was delivered by osmotic pump for 4 weeks. LSKL significantly reduced tumor burden as detected by a $75 \%$ reduction in human $\mathrm{Ig}$ kappa levels at 28 days of treatment and by bioluminescence imaging (Figure 2, A and B). Active TGF- $\beta$ signaling in the bone marrow of LSKL-treated mice as measured by staining for phospho-Smad2 was reduced significantly, establishing that LSKL is able to target the bone marrow and that LSKL has the predicted effect on TGF- $\beta$ activity (Figure 2C).

In the second model, we used highly osteolytic and aggressive human CAG-hpse cells with engineered overexpression of heparanase injected systemically by tail vein into SCID mice to better represent the systemic nature of the human disease. Heparanase expression by myeloma cells has been linked to extensive bone destruction and more aggressive disease. ${ }^{35,40-42}$ In this model, we also used SRI31277, which has improved in vivo stability. SRI31277 had dose-dependent effects on reducing MM tumor burden over time as measured by serum human Ig kappa levels (Figure 3A). Bioluminescence imaging of mice confirmed the reduction in tumor burden in mice treated with $30 \mathrm{mg} / \mathrm{kg}$ per day SRI31277 (Figure 3B). SRI31277 also impacted

A
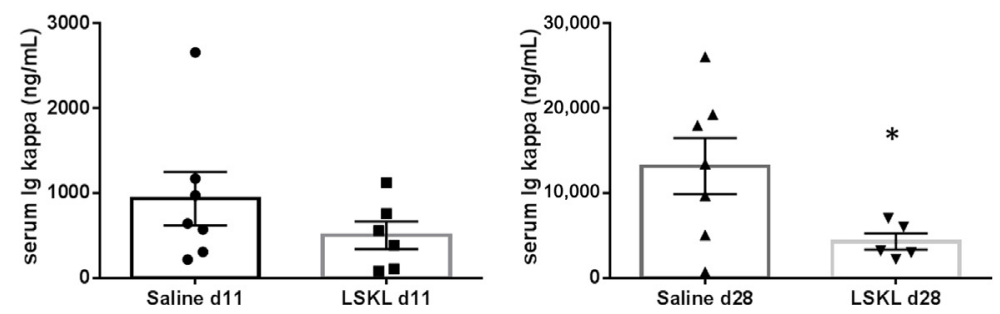

B

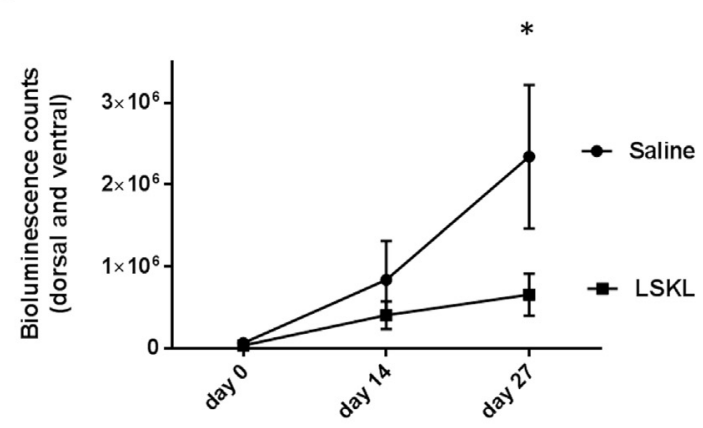

C

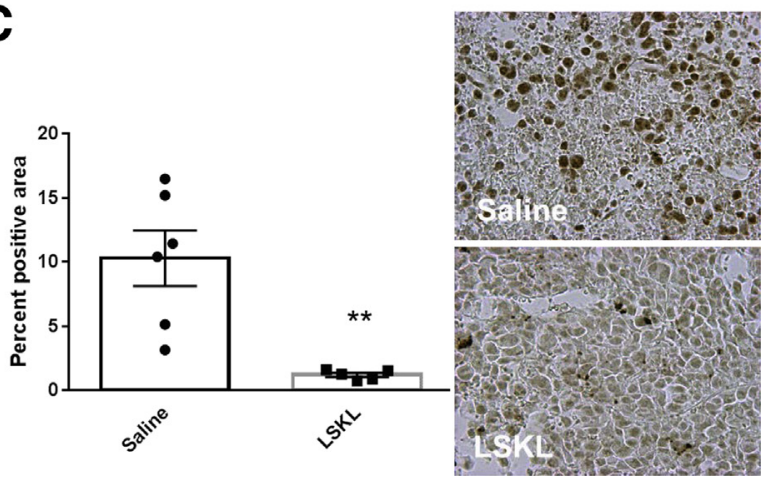

Figure 2 The thrombospondin1 (TSP1) antagonist peptide LSKL reduces tumor burden and transforming growth factor (TGF)- $\beta$ activity in the CAG intratibial model. A: Tumor burden was assessed by measuring human Ig kappa levels at days 11 and 28 after initiation of treatment with saline or $30 \mathrm{mg} / \mathrm{kg}$ per day LSKL peptide. Results are the means \pm SEM with individual values plotted for each group $(n=6$ to $7, P=0.016$ by unpaired $t$-test for day 28 . B: Tumor burden also was measured by bioluminescence imaging of luciferase-expressing CAG cells at days 14 and 27 . Results are the mean bioluminescence units (5 seconds exposure) of combined dorsal and ventral images \pm SEM, $P=0.02$ Holm-Sidak $t$-test. C: At 4 weeks of treatment, tibiae from mice injected with CAG cells were fixed and stained with anti-phospho-Smad2. Pixels of brown staining were quantified in four fields per animal. Five to six animals per group were analyzed. Data are the percent area exceeding the threshold for positive staining (brown). Data are the means \pm SEM with individual values plotted. $P=0.004$ by Mann-Whitney analysis. ${ }^{*} P<0.05,{ }^{*} P<0.01$. 
A

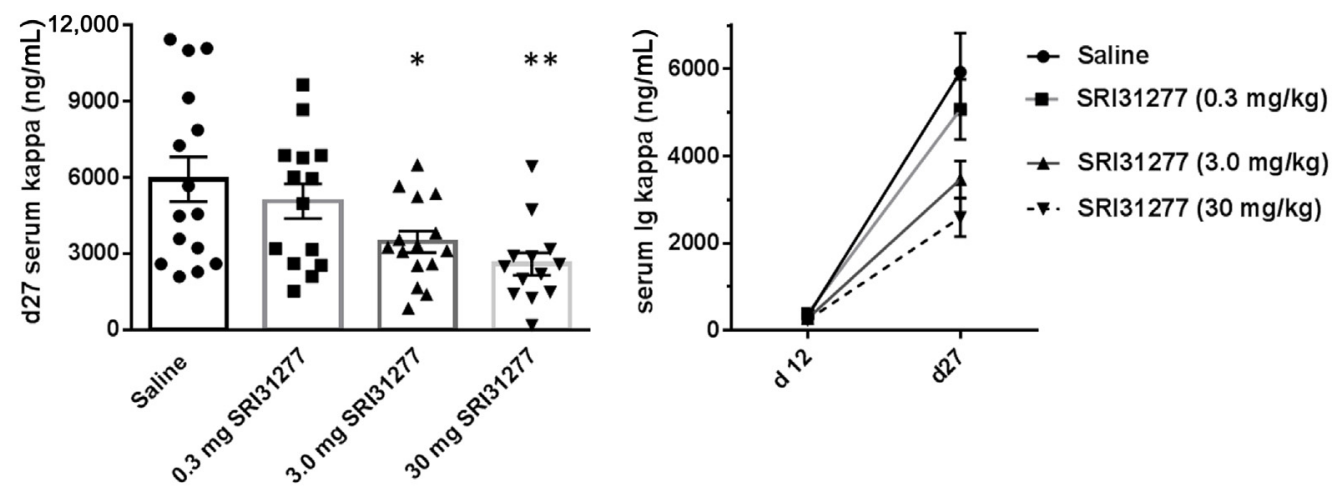

B
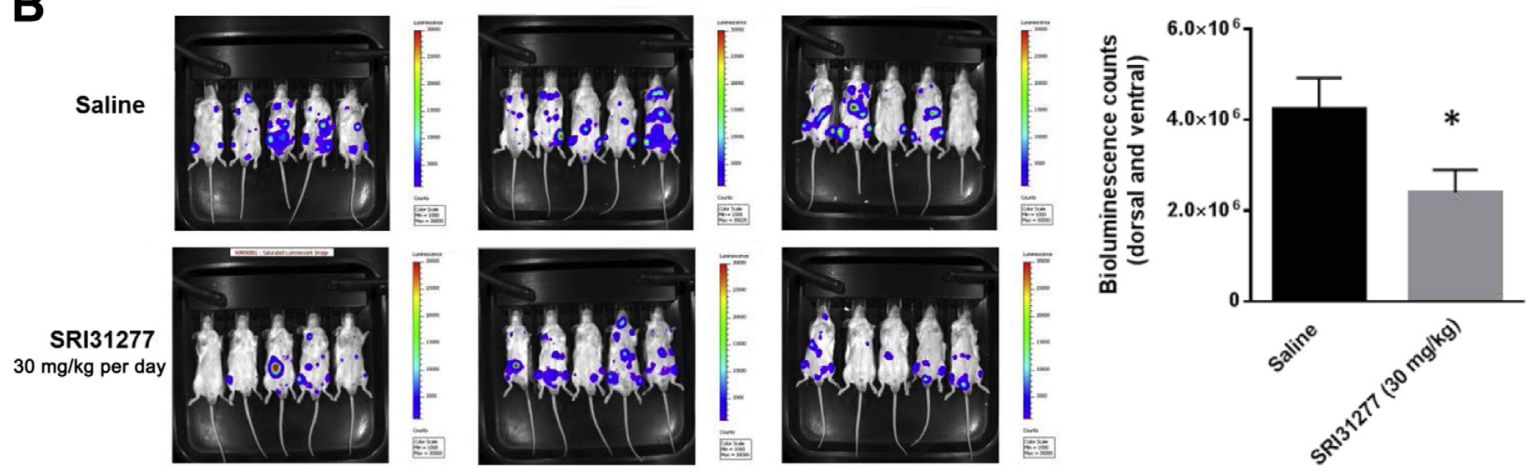

C

D
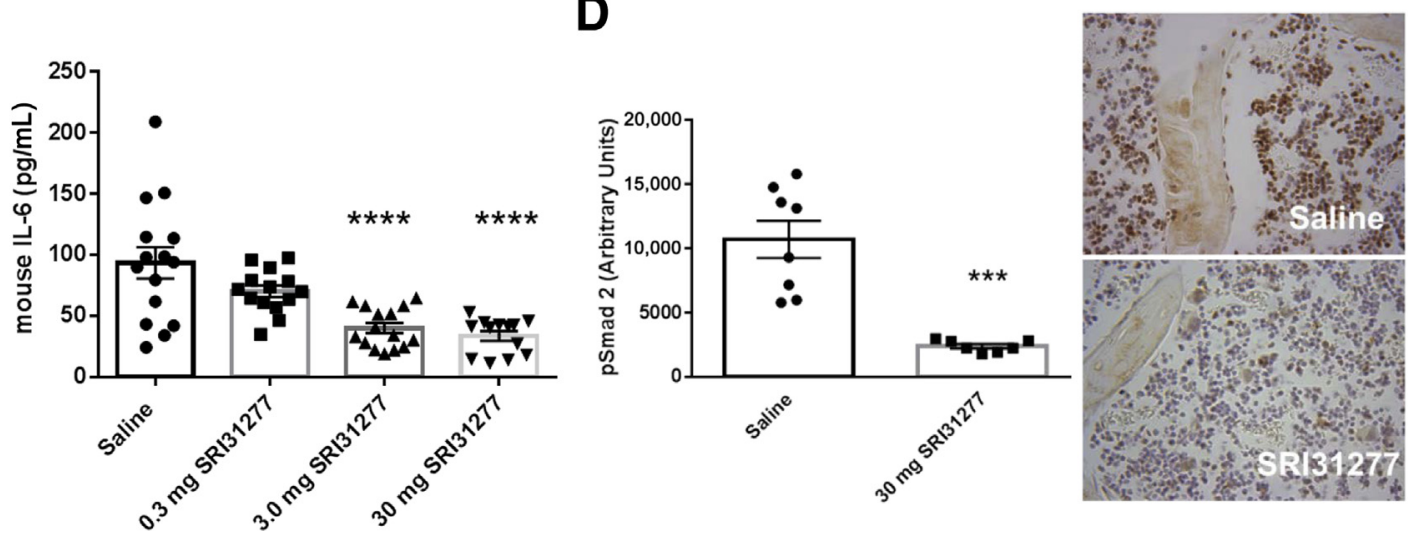

Figure 3 The thrombospondin1 (TSP1) antagonist SRI31277 has a dose-dependent effect in reduction of tumor burden, mouse IL-6, and transforming growth factor (TGF)- $\beta$ signaling in the systemic severe combined immunodeficiency-heparanase expressing CAG (SCID-CAG-hpse) model. CAGhpse myeloma cells expressing luciferase were injected into SCID mice via tail vein and tumors established for 12 days. A: Saline or SRI31277 (SKL) at $0.3,3.0$, or $30 \mathrm{mg} / \mathrm{kg}$ per day were delivered by osmotic pump starting on day 14 and treatments continued for 27 days. Unless indicated, all analyses were performed on serum samples obtained at day 27 or on tissue samples obtained at euthanasia on day 28 . Tumor burden was assessed by day 27 serum Ig kappa levels. Data are the means \pm SEM with individual results plotted ( $n=13$ to 15). Means on day 11 are not statistically different. For day 27 data: $P=0.04$, saline versus $3 \mathrm{mg} / \mathrm{kg}$ SRI31277; $P=0.004$, saline versus $30 \mathrm{mg} / \mathrm{kg}$ SRI31277, analysis of variance with Holm-Sidak. Results for serum Ig kappa levels are shown from serum obtained at days 11 and 27 after initiation of treatment (right panel). B: Bioluminescence imaging (5-second exposure) on day 26. Results are the mean bioluminescence counts of combined dorsal and ventral images \pm SEM. $P=0.037$, unpaired Student's $t$-test. C: Serum mouse IL- 6 was measured by enzyme-linked immunosorbent assay (versus saline, analysis of variance with Holm-Sidak). D: Femur sections stained for phospho-Smad2 ( $n=7$ animals per group) were analyzed and the means \pm SEM reflecting pixels of staining in arbitrary units were plotted, $P=0.0007$, unpaired $t$-test. Original magnification $\times 40$ (representative micrographs). ${ }^{\star} P<0.05$, ${ }^{* \star} P<0.005$, ${ }^{* * *} P<0.001$, and $* * * * P<0.0001$.

host stromal cells as mouse IL-6 levels were reduced by the compound (Figure 3C). SRI31277 also reduced phosphoSmad2 staining in the femoral bone marrow (Figure 3D). Staining for phospho-Smad2 was present in bone cells and in marrow cells in animals injected with CAG-hpse cells and treated with saline. Phospho-Smad2 staining in both the bone and marrow cells was reduced in SRI31277-treated animals. 
A

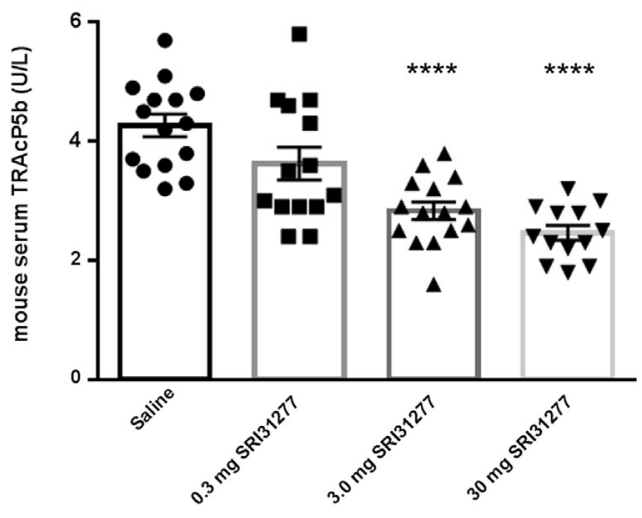

B

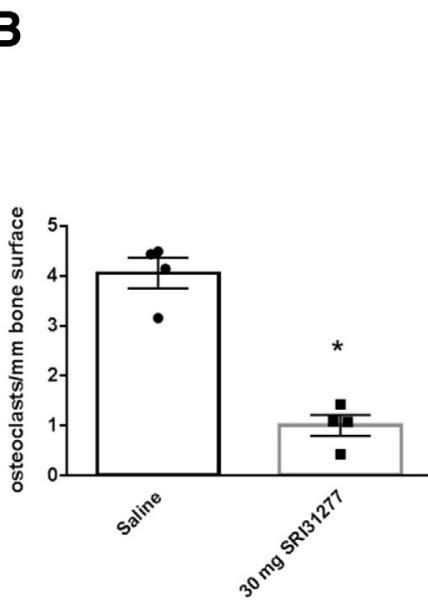

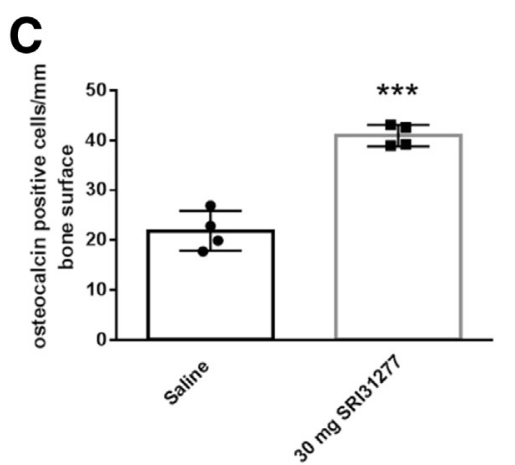

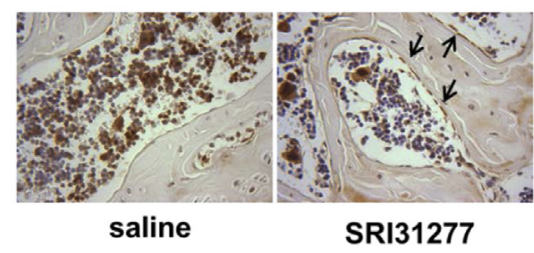

D
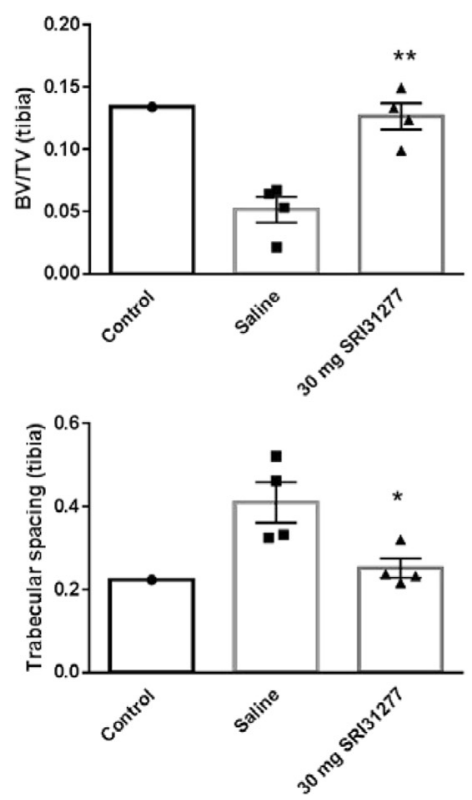

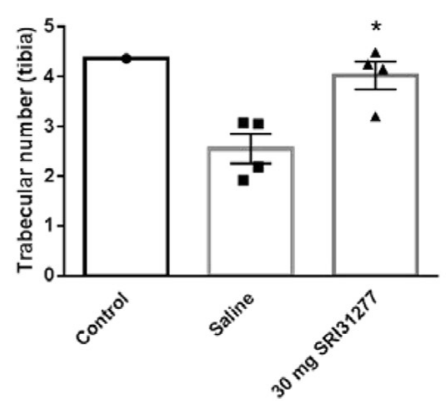

control

saline

SRI31277
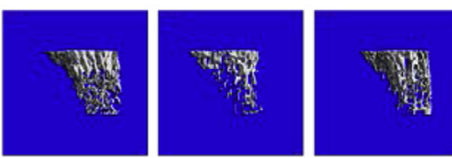

tibia

Figure 4 SRI31277 reduces osteolytic bone disease in the systemic severe combined immunodeficiency-heparanase expressing CAG (SCID-CAG-hpse) model. CAG-hpse myeloma cells expressing luciferase were injected into SCID mice via tail vein and tumors established for 12 days. Saline or SRI31277 at 0.3, 3.0, or 30 $\mathrm{mg} / \mathrm{kg}$ per day were delivered by osmotic pump starting on day 14, and treatments continued for 27 days. Unless indicated, all analyses were performed on

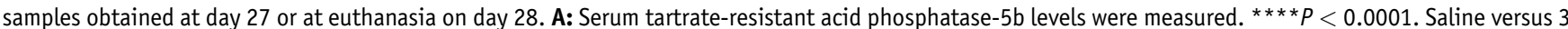
$\mathrm{mg} / \mathrm{kg}$ SRI31277, and saline versus $30 \mathrm{mg} / \mathrm{kg}$, SRI31277, ANOVA with Tukey post-hoc analysis). B and C: The number of tartrate acid resistant phosphatase (TRAP) staining osteoclasts (deep red cells) $(P=0.02$, unpaired $t$-test) $(\mathbf{B})$ or osteocalcin-positive osteoblasts (black arrows) (C) were determined per mm of bone surface in femur sections from four different mice per group. ${ }^{* *} P<0.001(P=0.0002)$, unpaired $t$-test. Results are means \pm SEM with individual values plotted. Original magnification: $\times 40$ (B and C). D: $\mu$ CT analyses of tibial bone density. Results are means \pm SEM from four animals per group $(P=0.002, \mathrm{BV} / \mathrm{TV}$; $P=0.026$, trabecular spacing; $P=0.011$, trabecular number for SRI31277 versus saline, unpaired $t$-test). Representative $\mu$ CT images are shown of mice injected systemically with CAG-hpse cells and treated with either saline or $30 \mathrm{mg} / \mathrm{kg}$ per day SRI31277, as compared with a control SCID mouse not injected with myeloma cells. ${ }^{*} P<0.05,{ }^{* *} P<0.01,{ }^{* *} P<0.001$, and ${ }^{* * *} P<0.0001$. $\mu \mathrm{CT}$, microcomputed tomography.

Importantly, indicators of osteolytic bone disease were reduced by treatment: SRI31277 decreased serum tartrate-resistant acid phosphatase-5b and osteoclast number and increased osteoblast number in femurs, and prevented loss of bone density as measured by $\mu \mathrm{CT}$ of tibiae (Figure 4, A-D).
SRI31277 Reduces Tumor Burden in the Mouse 5TGM1 Model

To determine whether the TSP1 antagonist is effective in other mouse models of myeloma, we used the 5TGM1 model of mouse myeloma on an immunocompetent background. ${ }^{39}$ The 


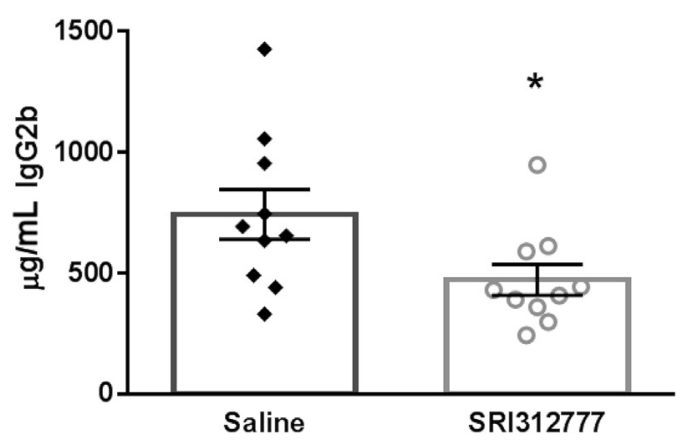

Figure 5 SRI31277 is effective in the immunocompetent 5TGM1 model. 5TGM1 cells engineered to stably expressed luciferase $\left(1 \times 10^{6}\right.$ cells $)$ were injected into the lateral tail veins of syngenic C57BL/KaLwRij mice. Treatment with either saline or $30 \mathrm{mg} / \mathrm{kg}$ per day SRI31277 delivered by osmotic pump was initiated on day 9 after tumor cell injection and continued for 27 days $(n=10$ per group). Tumor burden was measured on day 27 by evaluation of serum mouse IgG2b by enzyme-linked immunosorbent assay. Results are presented as means \pm SEM $\left[{ }^{*} P<0.05(P=0.039)\right.$, unpaired $t$-test $]$.

5TGM1 cells do not respond to active TGF- $\beta$ or express TSP1, but TSP1 can activate latent TGF- $\beta$ produced by these cells and SRI31277 blocks activation (Figure 1). Similar to results with the CAG and CAG-hpse human myeloma cells in the SCID models, SRI31277 reduced tumor burden as measured by decreased serum $\operatorname{IgG} 2 \mathrm{~b}$ on day 27 of treatment (Figure 5).

\section{SRI31277 in Combination with Bortezomib Has Increased Effectiveness}

We tested for possible synergistic effects of SRI31277 with two drugs currently used to treat myeloma patients, dexamethasone and bortezomib. Tumor burden was reduced to similar levels by either SRI31277 (2.1 mg/kg per week), dexamethasone ( $1 \mathrm{mg} / \mathrm{kg}$ per week, 1 time per week), or bortezomib $(2 \mathrm{mg} / \mathrm{kg}$ per week, 2 times per week) alone. However, the combination of SRI31277 and bortezomib showed a significantly greater reduction in tumor burden than either drug alone at both 11 and 24 days of treatment (Figure 6, A-C). The enhanced benefit was particularly evident at day 11 , when the combined drugs showed $87 \%$ reduction in tumor burden as compared to $46 \%$ to $48 \%$ inhibition with either SRI31277 or bortezomib alone. At day 24, the activity of SRI31277 and bortezomib was comparable (76\% reduction with SRI31277, 73\% reduction with bortezomib), and tumor burden was reduced by $89 \%$ when SRI31277 and bortezomib were combined. Dexamethasone in combination with SRI31277 at day 24 showed a nonsignificant reduction in tumor burden (74\%) as compared to dexamethasone alone (64\%), although this combination did not differ from SRI31277 alone (76\%).

In an attempt to understand these findings, we asked whether dexamethasone or bortezomib altered TGF- $\beta$ signaling, TSP1dependent TGF- $\beta$ activation, or expression of TSP1. Neither dexamethasone nor bortezomib directly affect TGF- $\beta-$ and TSP1-dependent Smad2 phosphorylation in CAG-hpse MM cells. A 1-hour pretreatment with dexamethasone did not affect TGF- $\beta$ - or TSP1-dependent Smad2 phosphorylation (Figure 7, $\mathrm{A}$ and $\mathrm{B}$, respectively). Only high-concentration bortezomib (100 nmol/L) modestly increased TGF- $\beta$ stimulated, but not TSP1-dependent, Smad phosphorylation after 2 hours of total exposure to the drug (Figure 7, A and B). Interestingly, 50 and $100 \mathrm{nmol} / \mathrm{L}$ dexamethasone and $100 \mathrm{nmol} / \mathrm{L}$ bortezomib increased TSP1 mRNA levels at 6 hours of treatment, although only $100 \mathrm{nmol} / \mathrm{L}$ dexamethasone increased TSP1 protein at 12 hours (Figure 7, C and D). However, CAG-hpse cells treated with 50 and $100 \mathrm{nmol} / \mathrm{L}$ bortezomib had significantly decreased viability at 12 hours, consistent with a reported in vitro $\mathrm{IC}_{50}$ of $7.3 \mathrm{nmol} / \mathrm{L}$ bortezomib for CAG cells. ${ }^{43}$

\section{Discussion}

Our data establish TSP1 as a significant regulator of latent TGF- $\beta$ activation in multiple mouse models of myeloma.
A

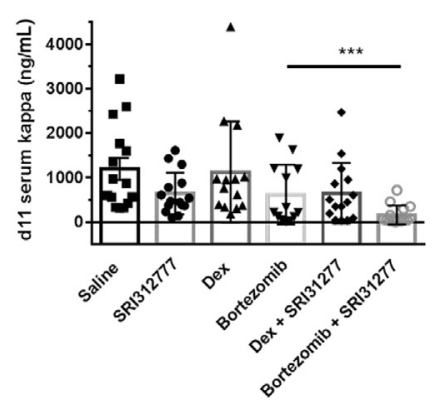

B

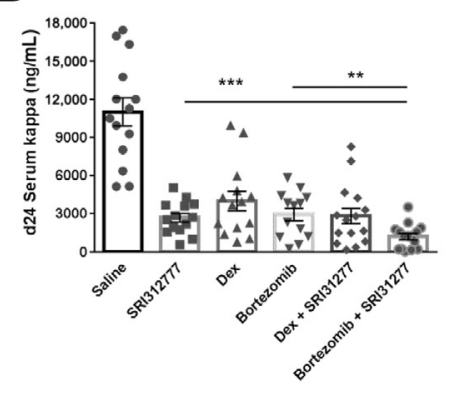

C

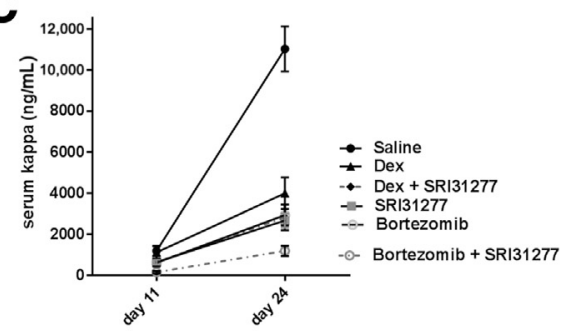

Figure 6 SRI31277 is as effective as either dexamethasone (dex) or bortezomib, and bortezomib and SRI31277 together have increased benefit in reducing myeloma tumor burden. Severe combined immunodeficiency mice were injected with heparanase-expressing CAG human myeloma cells expressing luciferase via tail vein. After 2 weeks, treatment with saline or $0.3 \mathrm{mg} / \mathrm{kg}$ per day SRI31277 delivered by osmotic pump was initiated. Some groups received via i.p. injection $1 \mathrm{mg} / \mathrm{kg}$ dexamethasone once per week or $1 \mathrm{mg} / \mathrm{kg}$ bortezomib twice per week. In addition, two groups were treated with SRI31277 + dexamethasone or SRI31277 + bortezomib ( $n=15$ per group). Treatments continued for approximately 4 weeks. A and B: Serum human Ig kappa levels were measured after 11 (A) and 24 (B) days of treatment. C: Tumor progression over time. Results are the means \pm SEM with individual values plotted. For day $11, P=0.00015$, unpaired $t$-test with Welch correction. For day $24, P=0.0034$, bortezomib versus SR31277 + bortezomib; and $P=0.0017$, SRI31277 versus SRI31277 + bortezomib, unpaired $t$-test. ${ }^{* *} P<0.01,{ }^{* * *} P<0.001$. 
A
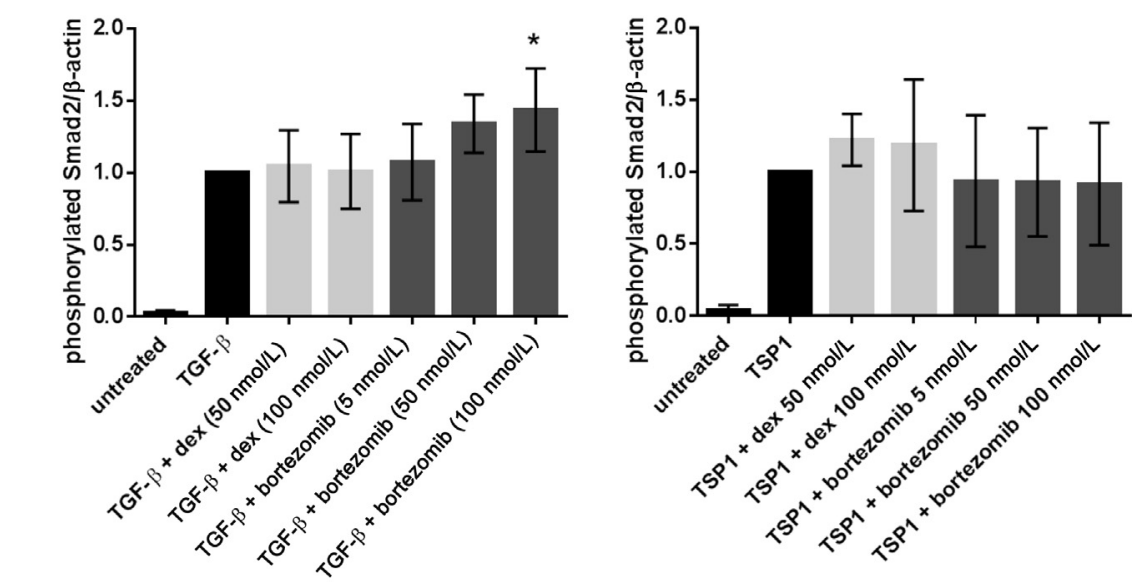

C

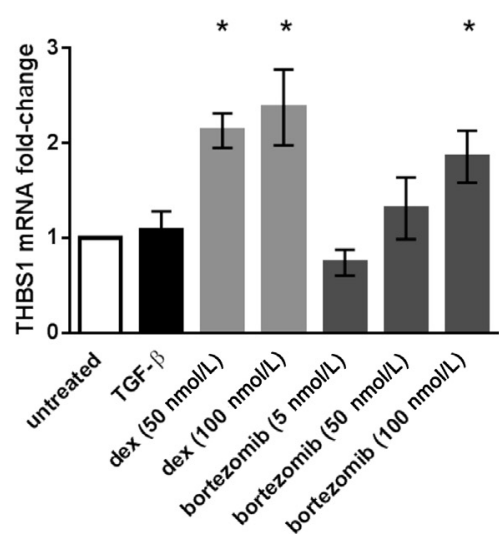

D

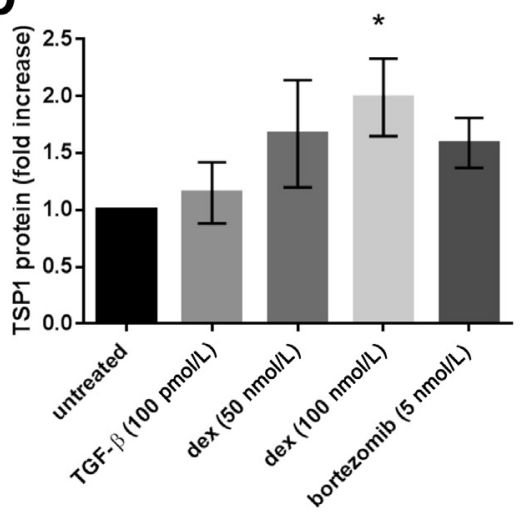

Figure 7 Dexamethasone (dex) and bortezomib do not affect thrombospondin1 (TSP1) stimulation of transforming growth factor (TGF)- $\beta$ activity or TGF- $\beta$ signaling by heparanase expressing CAG (CAG-hpse) cells. CAG-hpse cells $\left(2 \times 10^{5}\right)$ were seeded overnight in RPMI with $0.5 \%$ fetal bovine serum and then treated for 1 hour with 50 or 100 $\mathrm{nmol} / \mathrm{L}$ dexamethasone or 5,50 , or $100 \mathrm{nmol} / \mathrm{L}$ bortezomib. A and B: Cells then were treated for 1 hour with either $100 \mathrm{pmol} / \mathrm{L}$ TGF- $\beta$ (A) or $20 \mu \mathrm{g} / \mathrm{mL}$ TSP1 (B). Cell lysates were analyzed for phosphoSmad2 by Western blot analysis. Densitometric analyses are normalized to $\beta$-actin. Results are the means \pm SD of five to six separate experiments. C: CAG-hpse cells $\left(5 \times 10^{5}\right)$ were treated with 100 pmol/L TGF- $\beta, 50$ or $100 \mathrm{nmol} / \mathrm{L}$ dexamethasone, or 5,50 , or $100 \mathrm{nmol} / \mathrm{L}$ bortezomib in RPMI with $1 \%$ fetal bovine serum for 6 hours. RNA was harvested and analyzed for THBS1 mRNA by RT-PCR. THBS1 levels were normalized to GAPDH. D: Cells were treated as above in serum-free media for 12 hours and cell lysates harvested for Western blot analysis for TSP1. Densitometric analysis was performed and bands were normalized to $\beta$-actin. For C and $\mathbf{D}$, results are the means \pm SD from three separate experiments. ${ }^{*} P<0.05$ versus untreated, analysis of variance with Tukey analysis.
TSP1 activates latent TGF- $\beta$ produced by human myeloma and bone marrow cells in vitro, and importantly, LSKLbased antagonists reduce myeloma tumor burden, serum IL-6, osteolytic bone disease, and TGF- $\beta$ signaling in the bone marrow in vivo. These TSP1 antagonists reduce myeloma tumor burden in both immunocompetent and immunodeficient models. Furthermore, we showed that the LSKL-derived compound SRI31277 is as effective as dexamethasone or bortezomib alone, but that SRI31277 in combination with bortezomib has increased anti-myeloma activity.

The primary source of TSP1 in the myeloma microenvironment is likely from the microenvironment itself, rather than the myeloma cells. Although we detected message and protein for TSP1 in the human myeloma cell lines tested, these levels were low, and cultured myeloma cells had either low or nondetectable levels of active TGF- $\beta$ in the absence of added TSP1. Furthermore, SRI31277 reduced tumor burden in the mouse 5TGM1 model, in which the mouse 5TGM1 myeloma cells do not express TSP1. Immunohistochemical analysis of bone marrow sections of mice injected with CAG-hpse cells showed robust expression of TSP1 in multinucleated osteoclasts and to a lesser extent in osteocytes, megakaryocytes, and mononuclear cells of the bone marrow (data not shown).
Our studies suggest that TSP1-regulated latent TGF- $\beta$ activation plays a role in osteolytic bone disease in MM. TSP1 plays multiple roles in osteoblast and osteoclast biology, potentially through both TGF- $\beta$-dependent and -independent mechanisms. TSP1 is expressed in long bones, especially during early osteogenesis, and TSP1 inhibits matrix mineralization of MC3T3-E1 osteoblast-like cells and inhibits bone nodule formation. ${ }^{32,44,45}$ Previous work from our laboratory showed that bone marrow mesenchymal stem cells express TSP1, and TSP1-TGF- $\beta$ activation blocks osteogenic differentiation of mesenchymal stem cells. ${ }^{33}$ TSP1 also plays a role in osteoclast-mediated bone resorption, potentially through TSP1 binding to CD36. ${ }^{46}$ Thbsl-null mice with TSP1 deficiency during development have reduced osteoclast development owing to increased inducible nitric oxide levels, an action of TSP1 mediated by CD36 or CD47 binding. ${ }^{47}$ Interestingly TSP1 binding to macrophage CD36 is required for TSP1-mediated latent TGF- $\beta$ activation by bleomycin-stimulated alveolar macrophages. ${ }^{48}$

The role of TSP1 in TGF- $\beta$ activation by osteoclasts has not been explored. Osteoclasts in bone marrow from mice injected with CAG-hpse cells are strongly positive for TSP1 staining (data not shown). TSP1 binding to CD47 on myeloma cells is required for osteoclast-like 
transdifferentiation of dendritic cells. ${ }^{24}$ Antibody to TSP1 blocks osteoclast-mediated bone resorption in vitro; it is not known if this is due to blockade of TSP1-CD47 signaling or potentially due to TSP-CD47 interactions that facilitate TGF- $\beta$ activation. ${ }^{24,49}$ Data from the osteolytic mouse models implicate the TSP1-TGF- $\beta$ pathway in myeloma catabolic bone disease. Importantly, blockade of the TSP1-TGF- $\beta$ pathway affects both the osteoclast and osteoblast arms of bone remodeling. Therapeutically, it would be advantageous to both positively regulate osteoblasts and negatively impact osteoclast activity to avoid complications from agents that target only osteoclast activity such as zoledronic acid used in myeloma treatments.

Dexamethasone and bortezomib are used in the treatment of myeloma. Both have been reported to alter TGF- $\beta$ signaling. Dexamethasone increases TGF- $\beta$ expression in OPM-2 human myeloma cells and anti-TGF- $\beta$ antibodies partially block dexamethasone-mediated growth inhibition of these myeloma cells. ${ }^{50}$ Bortezomib inhibits Smad reporter activity and reduces TGF- $\beta$-dependent transcription in lung fibroblasts by increasing PPAR $\gamma$, but it did not reduce Smad phosphorylation or nuclear import. ${ }^{51}$ Because the TSP1 antagonist SRI31277 acts by reducing TGF- $\beta$ activation, we asked if there might be antagonism or co-operativity between SRI31277 and these drugs. SRI31277 was slightly more effective than dexamethasone at day 24 (76\% reduction in tumor burden with SRI31277 versus 64\% reduction with dexamethasone), although this difference was not statistically significant, and together these drugs did not show additional benefit as compared to SRI31277 alone (74\% reduction). In contrast, SRI31277 in combination with bortezomib had enhanced effectiveness as compared to either drug alone. However, the reasons are not clear, as neither drug directly impacts active TGF- $\beta$ signaling or TSP1-TGF- $\beta$ activation in CAG-hpse myeloma cells, and only high-dose dexamethasone increased TSP1 protein levels. Rather, these results could reflect cooperative mechanisms on cells of the myeloma bone marrow microenvironment.

These data support the utility of this targeted strategy to regulate TGF- $\beta$ activity. Previously, we defined the mechanism of TGF- $\beta$ activation by TSP1 and validated the efficacy and action of a peptide antagonist of this pathway as a therapeutic strategy in multiple animal models without observed toxicity with 15 weeks of treatment. ${ }^{31}$ This lack of toxicity is supported by recent studies examining gastrointestinal tumors in mice with mutations that reduce basal TGF- $\beta$ activity combined with mutations in different TGF- $\beta$ activators. Although mice with this background and a second mutation in the TGF- $\beta$ activating integrin $\beta_{8}$ showed inflammation and higher tumor numbers, there was no statistical increase in tumors in compound mutant mice with loss of TSP $1 .^{52}$ Similarly, necropsy of mice treated continuously for 4 weeks with LSKL or SRI31277 showed no incidence of nonmyeloma secondary tumors or inflammation [Trent Schoeb (UAB), data not shown]. This approach also avoids potential complications from pan-
TSP1 inhibitory approaches that might lead to increased angiogenesis, altered inflammation, and increased nitric oxide signaling owing to its many TGF- $\beta$ independent functions.

TGF- $\beta$ influences MM progression through its effects on bone catabolism, immune dysfunction, and hematopoietic stem cells. ${ }^{2,3,5,13,53,54}$ However, there are no clinical trials investigating TGF- $\beta$ antagonists for the treatment of myeloma, despite evidence of its role in myeloma progression and complications. TGF- $\beta$ is critical for homeostasis: genetic ablation of TGF- $\beta$, its receptors, or signaling mediators results in developmental defects, inflammation, and increased carcinomas. Thus, it is therapeutically advantageous to target only adverse TGF- $\beta$ activity in myeloma and spare homeostatic activity. Current anti-TGF- $\beta$ therapeutics target the molecule itself or downstream signaling pathways and provide no mechanism for distinguishing between homeostatic and disease-related TGF- $\beta$ activity, raising the potential for adverse effects. In fact, Smad2 resistance and increased papilloma incidence in mice treated for 20 weeks with a TGF- $\beta$ receptor kinase inhibitor were identified, ${ }^{55}$ and the 1 D11 pan-specific anti-TGF- $\beta$ neutralizing antibody shows epithelial hyperplasia and progression to carcinoma in some models. ${ }^{56} \mathrm{~A}$ more targeted approach to reducing disease-specific TGF- $\beta$ activity will have increased therapeutic benefit, a point echoed in discussions of therapeutic approaches to controlling TGF- $\beta$ in malignancies. ${ }^{14,56}$ The efficacy of the TSP1 antagonist compounds and the lack of associated toxicities suggest the promise of this approach. Because the major effects of the TSP1 antagonist appear to be on the tumor microenvironment rather than on myeloma cell viability itself, the TSP1 antagonist could be used to modulate the myeloma bone marrow microenvironment after high-dose therapy or during maintenance to induce a bone marrow microenvironment more resistant to myeloma cell growth.

\section{Acknowledgments}

We thank Dr. Ralph D. Sanderson (UAB) for cells and helpful discussions on the myeloma animal models, Dr. Trent Schoeb (UAB) for necropsy analyses of mice, Ray Moore (UAB Metabolomics Core) for analysis of LSKL peptides in serum, Li Nan for assistance with tumor cell injections, and Dr. Sejong Bae (Biostatistics and Bioinformatics Shared Facility of the Comprehensive Cancer Center) for assistance with statistical analyses of the drug combination studies. We thank the UAB Comprehensive Cancer Center Small Animal Imaging Shared Facility, the small animal phenotyping core for the $\mu \mathrm{CT}$ analyses, the UAB Bone Histomorphometry Core, and the Alabama Drug Discovery Alliance mentoring committee led by Dr. Maaike Everts for expert guidance.

A.L., M.A.P., and W.L. performed the experiments and wrote the manuscript. H.H. performed the cell proliferation 
studies. Y.Y. provided cells, animals, assistance with cell injections, and intellectual input into the design and conduct of the experiments. M.J.S. designed the LSKL peptide analogs. J.E.M.-U. conceived the study, supervised data collection, and wrote the manuscript with the assistance of Drs. Y.Y. and M.J.S.

\section{Supplemental Data}

Supplemental material for this article can be found at http://dx.doi.org/10.1016/j.ajpath.2015.11.003.

\section{References}

1. Anderson KC, Carrasco RD: Pathogenesis of myeloma. Annu Rev Pathol 2011, 6:249-274

2. Takeuchi K, Abe M, Hiasa M, Oda A, Amou H, Kido S, Harada T, Tanaka O, Miki H, Nakamura S, Nakano A, Kagawa K, Yata K, Ozaki S, Matsumoto T: TGF-Beta inhibition restores terminal osteoblast differentiation to suppress myeloma growth. PLoS One 2010, 5:e9870

3. Urashima M, Ogata A, Chauhan D, Hatziyanni M, Vidriales MB, Dedera DA, Schlossman RL, Anderson KC: Transforming growth factor-beta1: differential effects on multiple myeloma versus normal B cells. Blood 1996, 87:1928-1938

4. Isufi I, Seetharam M, Zhou L, Sohal D, Opalinska J, Pahanish P, Verma A: Transforming growth factor-beta signaling in normal and malignant hematopoiesis. J Interferon Cytokine Res 2007, 27: $543-552$

5. Matsumoto T, Abe M: TGF-beta-related mechanisms of bone destruction in multiple myeloma. Bone 2011, 48:129-134

6. Brown R, Murray A, Pope B, Sze DM, Gibson J, Ho PJ, Hart D, Joshua D: Either interleukin-12 or interferon-gamma can correct the dendritic cell defect induced by transforming growth factor beta in patients with myeloma. Br J Haematol 2004, 125:743-748

7. Hayashi $T$, Hideshima $T$, Nguyen AN, Munoz O, Podar K, Hamasaki M, Ishitsuka K, Yasui H, Richardson P, Chakravarty S, Murphy A, Chauhan D, Higgins LS, Anderson KC: Transforming growth factor beta receptor I kinase inhibitor down-regulates cytokine secretion and multiple myeloma cell growth in the bone marrow microenvironment. Clin Cancer Res 2004, 10:7540-7546

8. Wen J, Tao W, Kuiatse I, Lin P, Feng Y, Jones RJ, Orlowski RZ, $\mathrm{Zu}$ Y: Dynamic balance of multiple myeloma clonogenic side population cell percentages controlled by environmental conditions. Int $\mathbf{J}$ Cancer 2015, 136:991-1002

9. Breen EC, Ignotz RA, McCabe L, Stein JL, Stein GS, Lian JB: TGF beta alters growth and differentiation related gene expression in proliferating osteoblasts in vitro, preventing development of the mature bone phenotype. J Cell Physiol 1994, 160:323-335

10. Ruan M, Pederson L, Bradley EW, Bamberger AM, Oursler MJ: Transforming growth factor-\{beta\} coordinately induces suppressor of cytokine signaling 3 and leukemia inhibitory factor to suppress osteoclast apoptosis. Endocrinology 2010, 151:1713-1722

11. Gingery A, Bradley EW, Pederson L, Ruan M, Horwood NJ, Oursler MJ: TGF-beta coordinately activates TAK1/MEK/AKT/NFkB and SMAD pathways to promote osteoclast survival. Exp Cell Res 2008, 314:2725-2738

12. Frassanito MA, Rao L, Moschetta M, Ria R, Di Marzo L, De Luisi A, Racanelli V, Catacchio I, Berardi S, Basile A, Menu E, Ruggieri S, Nico B, Ribatti D, Fumarulo R, Dammacco F, Vanderkerken K, Vacca A: Bone marrow fibroblasts parallel multiple myeloma progression in patients and mice: in vitro and in vivo studies. Leukemia 2014, 28:904-916
13. Bruns I, Cadeddu RP, Brueckmann I, Frobel J, Geyh S, Bust S, Fischer JC, Roels F, Wilk CM, Schildberg FA, Hunerliturkoglu AN, Zilkens C, Jager M, Steidl U, Zohren F, Fenk R, Kobbe G, Brors B, Czibere A, Schroeder T, Trumpp A, Haas R: Multiple myeloma-related deregulation of bone marrow-derived CD34+ hematopoietic stem and progenitor cells. Blood 2012, 120:2620-2630

14. Flavell RA, Sanjabi S, Wrzesinski SH, Licona-Limon P: The polarization of immune cells in the tumour environment by TGFbeta. Nat Rev Immunol 2010, 10:554-567

15. Annes JP, Munger JS, Rifkin DB: Making sense of latent TGFbeta activation. J Cell Sci 2003, 116:217-224

16. Wipff PJ, Hinz B: Integrins and the activation of latent transforming growth factor beta1: an intimate relationship. Eur J Cell Biol 2008, $87: 601-615$

17. Murphy-Ullrich JE, Poczatek M: Activation of latent TGF-beta by thrombospondin-1: mechanisms and physiology. Cytokine Growth Factor Rev 2000, 11:59-69

18. Sweetwyne MT, Murphy-Ullrich JE: Thrombospondin1 in tissue repair and fibrosis: TGF-beta-dependent and independent mechanisms. Matrix Biol 2012, 31:178-186

19. Murphy-Ullrich JE, Sage EH: Revisiting the matricellular concept. Matrix Biol 2014, 37:1-14

20. Stenina-Adognravi O: Invoking the power of thrombospondins: regulation of thrombospondins expression. Matrix Biol 2014, 37: $69-82$

21. Rogers NM, Sharifi-Sanjani M, Csanyi G, Pagano PJ, Isenberg JS: Thrombospondin-1 and CD47 regulation of cardiac, pulmonary and vascular responses in health and disease. Matrix Biol 2014, 37: 92-101

22. Ludek P, Hana S, Zdenek A, Martina A, Dana K, Tomas B, Lucie K, Marta K, Jaroslav M, Miroslav P, Jiri V, Roman H: Treatment response to bortezomib in multiple myeloma correlates with plasma hepatocyte growth factor concentration and bone marrow thrombospondin concentration. Eur J Haematol 2010, 84:332-336

23. Rendtlew Danielsen JM, Knudsen LM, Dahl IM, Lodahl M, Rasmussen T: Dysregulation of CD47 and the ligands thrombospondin 1 and 2 in multiple myeloma. Br J Haematol 2007, 138: $756-760$

24. Kukreja A, Radfar S, Sun BH, Insogna K, Dhodapkar MV: Dominant role of CD47-thrombospondin-1 interactions in myeloma-induced fusion of human dendritic cells: implications for bone disease. Blood 2009, 114:3413-3421

25. Murphy-Ullrich JE, Iozzo RV: Thrombospondins in physiology and disease: new tricks for old dogs. Matrix Biol 2012, 31:152-154

26. Ribeiro SM, Poczatek M, Schultz-Cherry S, Villain M, MurphyUllrich JE: The activation sequence of thrombospondin-1 interacts with the latency-associated peptide to regulate activation of latent transforming growth factor-beta. J Biol Chem 1999, 274: 13586-13593

27. Young GD, Murphy-Ullrich JE: Molecular interactions that confer latency to transforming growth factor-beta. J Biol Chem 2004, 279: 38032-38039

28. Yee KO, Streit M, Hawighorst T, Detmar M, Lawler J: Expression of the type-1 repeats of thrombospondin-1 inhibits tumor growth through activation of transforming growth factor-beta. Am J Pathol 2004, 165:541-552

29. Crawford SE, Stellmach V, Murphy-Ullrich JE, Ribeiro SM, Lawler J, Hynes RO, Boivin GP, Bouck N: Thrombospondin-1 is a major activator of TGF-betal in vivo. Cell 1998, 93: $1159-1170$

30. Belmadani S, Bernal J, Wei CC, Pallero MA, Dell'italia L, MurphyUllrich JE, Berecek KH: A thrombospondin-1 antagonist of transforming growth factor-beta activation blocks cardiomyopathy in rats with diabetes and elevated angiotensin II. Am J Pathol 2007, 171: 777-789

31. Lu A, Miao M, Schoeb TR, Agarwal A, Murphy-Ullrich JE: Blockade of TSP1-dependent TGF-beta activity reduces renal injury 
and proteinuria in a murine model of diabetic nephropathy. Am J Pathol 2011, 178:2573-2586

32. Ueno A, Miwa Y, Miyoshi K, Horiguchi T, Inoue H, Ruspita I, Abe K, Yamashita K, Hayashi E, Noma T: Constitutive expression of thrombospondin 1 in MC3T3-E1 osteoblastic cells inhibits mineralization. J Cell Physiol 2006, 209:322-332

33. Bailey Dubose K, Zayzafoon M, Murphy-Ullrich JE: Thrombospondin-1 inhibits osteogenic differentiation of human mesenchymal stem cells through latent TGF-beta activation. Biochem Biophys Res Commun 2012, 422:488-493

34. Borset M, Hjertner O, Yaccoby S, Epstein J, Sanderson RD: Syndecan-1 is targeted to the uropods of polarized myeloma cells where it promotes adhesion and sequesters heparin-binding proteins. Blood 2000, 96:2528-2536

35. Yang Y, Macleod V, Bendre M, Huang Y, Theus AM, Miao HQ, Kussie P, Yaccoby S, Epstein J, Suva LJ, Kelly T, Sanderson RD: Heparanase promotes the spontaneous metastasis of myeloma cells to bone. Blood 2005, 105:1303-1309

36. Oyajobi BO, Franchin G, Williams PJ, Pulkrabek D, Gupta A, Munoz S, Grubbs B, Zhao M, Chen D, Sherry B, Mundy GR: Dual effects of macrophage inflammatory protein-1alpha on osteolysis and tumor burden in the murine 5TGM1 model of myeloma bone disease. Blood 2003, 102:311-319

37. Schultz-Cherry S, Murphy-Ullrich JE: Thrombospondin causes activation of latent transforming growth factor-beta secreted by endothelial cells by a novel mechanism (published correction appears in $\mathrm{J}$ Cell Biol 1993;122[5]:following 1143). J Cell Biol 1993, 122 : 923-932

38. Annis DS, Murphy-Ullrich JE, Mosher DF: Function-blocking antithrombospondin-1 monoclonal antibodies. J Thromb Haemost 2006, 4:459-468

39. Garrett IR, Dallas S, Radl J, Mundy GR: A murine model of human myeloma bone disease. Bone 1997, 20:515-520

40. Kelly T, Miao HQ, Yang Y, Navarro E, Kussie P, Huang Y, MacLeod V, Casciano J, Joseph L, Zhan F, Zangari M, Barlogie B, Shaughnessy J, Sanderson RD: High heparanase activity in multiple myeloma is associated with elevated microvessel density. Cancer Res 2003, 63:8749-8756

41. Purushothaman A, Hurst DR, Pisano C, Mizumoto S, Sugahara K, Sanderson RD: Heparanase-mediated loss of nuclear syndecan-1 enhances histone acetyltransferase (HAT) activity to promote expression of genes that drive an aggressive tumor phenotype. J Biol Chem 2011, 286:30377-30383

42. Yang Y, Ren Y, Ramani VC, Nan L, Suva LJ, Sanderson RD: Heparanase enhances local and systemic osteolysis in multiple myeloma by upregulating the expression and secretion of RANKL. Cancer Res 2010, 70:8329-8338

43. Weiss C, Uziel O, Wolach O, Nordenberg J, Beery E, Bulvick S, Kanfer G, Cohen O, Ram R, Bakhanashvili M, Magen-Nativ H, Shilo N, Lahav M: Differential downregulation of telomerase activity by bortezomib in multiple myeloma cells- multiple regulatory pathways in vitro and ex vivo. $\mathrm{Br} \mathrm{J}$ Cancer 2012, 107:1844-1852

44. Sherbina NV, Bornstein P: Modulation of thrombospondin gene expression during osteoblast differentiation in MC3T3-E1 cells. Bone 1992, 13:197-201

45. Alford AI, Hankenson KD: Matricellular proteins: extracellular modulators of bone development, remodeling, and regeneration. Bone 2006, 38:749-757

46. Carron JA, Wagstaff SC, Gallagher JA, Bowler WB: A CD36-binding peptide from thrombospondin-1 can stimulate resorption by osteoclasts in vitro. Biochem Biophys Res Commun 2000, 270:1124-1127

47. Amend SR, Uluckan O, Hurchla M, Leib D, Novack DV, Silva M, Frazier W, Weilbaecher KN: Thrombospondin-1 regulates bone homeostasis through effects on bone matrix integrity and nitric oxide signaling in osteoclasts. J Bone Miner Res 2015, 30:106-115

48. Yehualaeshet T, O’Connor R, Green-Johnson J, Mai S, Silverstein R, Murphy-Ullrich JE, Khalil N: Activation of rat alveolar macrophagederived latent transforming growth factor beta-1 by plasmin requires interaction with thrombospondin-1 and its cell surface receptor, CD36. Am J Pathol 1999, 155:841-851

49. Harpel JG, Schultz-Cherry S, Murphy-Ullrich JE, Rifkin DB: Tamoxifen and estrogen effects on TGF-beta formation: role of thrombospondin-1, alphavbeta3, and integrin-associated protein. Biochem Biophys Res Commun 2001, 284:11-14

50. Johnson BH, Gomi M, Jakowlew SB, Moriwaki K, Thompson EB: Actions and interactions of glucocorticoids and transforming growth factor beta on two related human myeloma cell lines. Cell Growth Differ 1993, 4:25-30

51. Mutlu GM, Budinger GR, Wu M, Lam AP, Zirk A, Rivera S, Urich D, Chiarella SE, Go LH, Ghosh AK, Selman M, Pardo A, Varga J, Kamp DW, Chandel NS, Sznajder JI, Jain M: Proteasomal inhibition after injury prevents fibrosis by modulating TGF-beta(1) signalling. Thorax 2012, 67:139-146

52. Shibahara K, Ota M, Horiguchi M, Yoshinaga K, Melamed J, Rifkin DB: Production of gastrointestinal tumors in mice by modulating latent TGF-beta1 activation. Cancer Res 2013, 73:459-468

53. Abe M, Hiura K, Ozaki S, Kido S, Matsumoto T: Vicious cycle between myeloma cell binding to bone marrow stromal cells via VLA-4-VCAM-1 adhesion and macrophage inflammatory protein1alpha and MIP-1beta production. J Bone Miner Metab 2009, 27 : $16-23$

54. Longo V, Brunetti O, D’Oronzo S, Dammacco F, Silvestris F: Therapeutic approaches to myeloma bone disease: an evolving story. Cancer Treat Rev 2012, 38:787-797

55. Connolly EC, Saunier EF, Quigley D, Luu MT, De Sapio A, Hann B, Yingling JM, Akhurst RJ: Outgrowth of drug-resistant carcinomas expressing markers of tumor aggression after long-term TbetaRI/II kinase inhibition with LY2109761. Cancer Res 2011, 71:2339-2349

56. Prud'homme GJ: Pathobiology of transforming growth factor beta in cancer, fibrosis and immunologic disease, and therapeutic considerations. Lab Invest 2007, 87:1077-1091 